\title{
Climate Change and Cultural Cognition
}

\author{
Penultimate Draft, Forthcoming in Philosophy and Climate Change \\ Daniel Greco
}

\section{Introduction}

\Much recent epistemology concerns the social dimensions of knowledge. While traditionally epistemology has mainly been concerned with the predicament of the individual knower, considered in abstraction from his or her community, in reality much of the information we have comes not from our own isolated investigations, but instead by trusting the testimony of others 1 An important task for socially situated knowers, then, is to identify knowledgeable individuals whose testimony we should seek out and rely on. Normally this task is straightforward, and doesn't raise any deep epistemological puzzles. If my toilet isn't flushing, I'll ask a plumber to tell me what's wrong, and how to fix it. And if I don't already know a reliable plumber, there are obvious, unproblematic strategies I can use to find one.

Sometimes, however, this task is less straightforward. Both descriptive questionshow do we decide whom to trust? - and normative ones - how should we decide whom to trust? - can be tricky $\left.\right|^{2}$ In this paper, I'll use the example of climate change to discuss a partial answer to the descriptive question of how we decide whom to trust: the cultural cognition thesis, according to which we treat individuals as knowledgeable

\footnotetext{
For helpful comments and discussion, thanks to Nathan Ballantyne, Tristram McPherson, Elizabeth Miller, and David Plunkett.

${ }^{1}$ See, e.g., Coady (1992), Lackey (2008).

${ }^{2}$ See Goldman (2001) for an instructive treatment of some of the difficulties involved in satisfactorily answering the latter question. The latter parts of this paper can be seen as an attempt to apply some of the general lessons Goldman suggests.
} 


\section{Climate Change and Cultural Cognition}

experts on factual questions of political import only insofar as they share our cultural worldview ${ }^{3}$ I'll go on to ask some normative questions about cultural cognition: should we think of it as a species of irrationality that must be overcome (or circumvented) if we are to communicate scientific results effectively, or should we instead think of it as an inescapable part of rational belief management? If it is irrational, why is that so? Answering these normative questions will require getting clearer on how and to what extent cultural cognition contrasts with other, putatively distinct strategies for learning from testimony, both rational (e.g., Bayesian conditionalization) and irrational (e.g., confirmation bias).

Before introducing the cultural cognition thesis, however, I want to head off a potential worry. Climate change might seem like a poor example to use to explore normative questions about deference to experts, because the answers can seem boringly, frustratingly easy. For instance, Elizabeth Anderson (2011, p.153) writes that "information needed for laypersons to make sound second-order judgments of the trustworthiness of testifiers about global warming is readily available. The criteria for making such judgments are evident and easy to apply to information on the Web." While there are certainly residual social and psychological questions about (1) why global warming is nevertheless still controversial, at least in the United States, and (2) how to best change people's minds about global warming $]^{4}$ epistemological questions about what we should take the relevant facts to be in the first place can seem philosophically uninterestingakin to questions about how to find a good plumber.

Whether previous worry is apt depends on just what questions about climate change we're considering. If the question is just whether anthropogenic global warming (AGW) is real-whether temperatures are rising, and will continue to rise, due to past and present human activity - then the worry is on point; not only is this question uncontro-

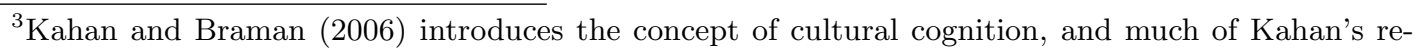
search since has been related to it.

${ }^{4}$ See, e.g., Oreskes (2011) and Jost (2015) for some discussion of these social and psychological questions.
} 


\section{Climate Change and Cultural Cognition}

versial among those who might plausibly belong to the community of relevant experts, but finding out that it is so is not a difficult matter. On this point, Anderson is persuasive. But questions about the magnitude and costs of AGW, as well as questions about the costs of policy responses to AGW, are more controversial. To take one significant example, some climate scientists have proposed various measures to mitigate the effects of AGW, such as releasing sulfate aerosols into the stratosphere, with the aim of scattering sunlight into space and thereby reducing the amount that reaches and warms earth $5^{5}$ Such "geoengineering" proposals have been harshly criticized by environmental groups, on the grounds that they are likely to have unintended harmful side effects, as well as to distract political actors from the necessity of reducing carbon emissions ${ }^{6} 7$

Concerning the issue of whether geoengineering should be taken seriously as a response to AGW, or dismissed as a dangerous distraction, normative questions about whom to trust are quite tricky. Moreover, as we'll see, responses to geoengineering proposals provide a nice example of evidence for the cultural cognition thesis. In the next section I'll introduce that thesis, as well as discuss its particular bearing on responses to geoengineering proposals.

\footnotetext{
${ }^{5}$ This technique, and more generally any effort aimed at reducing AGW by scattering or reflecting sunlight, is known as Solar Radiation Management (SRM). Along with Carbon Dioxide Removal (CDR), which aims at removing carbon dioxide from the atmosphere, it is one of the two main geoengineering strategies that has been proposed. See Keith (2013) for sympathetic explanation and discussion.

${ }^{6}$ For example, the ETC Group's "Hands Off Mother Earth" campaign, which will be discussed later. I don't mean to overstate the extent of the controversy - few if any credible voices are calling for geoengineering measures as a replacement for reducing emissions, rather than a supplement - they tend to stress that even in the best case scenarios for political action to reduce emissions temperatures may still rise quite a good deal, making additional responses worth considering. This is the stance taken by Keith (2013).

'The National Academies of Sciences, Engineering, and Medicine have recommended that the term "geoengineering" be replaced with talk of "climate intervention" (2015). While their arguments for this proposal strike me as cogent, the terminological change hasn't yet been widely adopted, so I use the older term to avoid confusion.
} 


\section{Climate Change and Cultural Cognition}

\section{Cultural Cognition}

The cultural cognition thesis says that individuals' cultural commitments, including values, are explanatorily prior to their beliefs about matters of fact. As Kahan and Braman (2006) put it, "individuals accept or reject empirical claims about the consequences of controversial polices based on their vision of a good society." (p. 148) In general, individuals will think that the policies that fit naturally into their cultural worldviews have independently good consequences 8 For example, concerning the death penalty, those who favor (oppose) it on moral/cultural grounds will go on to believe that it is effective (ineffective) in deterring crime (Kahan, 1999). Moreover, similar dynamics influence perceptions of who is a trustworthy expert. To the extent that one's cultural commitments fit with a policy of relatively unrestricted gun ownership (gun control), one will regard as more knowledgable and trustworthy (ignorant and unreliable) putative "experts" - who are reported to hold that laws permitting "concealed carry" decrease crime (Kahan et al., 2011). Of relevance to the present paper, Kahan et al. report similar results concerning perceptions of who is an expert about global warming, and nuclear power. While the sizes of cultural cognition effects vary from case to case, they are often substantial 9

\footnotetext{
${ }^{8}$ I talk here about "cultural worldviews", but in most of Kahan's research he talks more specifically about individualist/hierarchical worldviews and communitarian/egalitarian ones. The questions used to measure worldview are available in the appendix of Kahan et al. (2011).

${ }^{9}$ For instance, Kahan et al. (2011, p. 15) report that:

a plurality of hierarchical individualists $(47 \%)$ perceived that most expert scientists agree, a plurality of egalitarian communitarians $(47 \%)$ that most expert scientists disagree, that permitting citizens to carry handguns in public reduces crime. Only $10 \%$ of hierarchical individualists perceived that expert scientists disagree with this position, and only $12 \%$ of egalitarian communitarians that they agree with it.

They report similarly large effect sizes concerning perceptions of scientific consensus concerning global warming:

Solid majorities of egalitarian communitarians perceived that most expert scientists agree that global warming is occurring $(78 \%)$ and that it has an anthropogenic source $(68 \%)$. In contrast, $56 \%$ of hierarchical individualists believe that scientists are divided, and another $25 \%$ (as opposed to $2 \%$ for egalitarian communitarians) that most expert scientists disagree that global temperatures are increasing. Likewise, a majority of hierarchical individualists, $55 \%$, believed that most expert scientists are divided on whether humans are causing global warming, with another $32 \%$ perceiving that most expert scientists disagree with this
} 


\section{Climate Change and Cultural Cognition}

To get a clearer picture of just what cultural cognition is supposed to be, and how it is supposed to be distinctive, we can contrast it with the more familiar and general phenomenon of confirmation bias. Confirmation bias is the tendency to interpret new information as confirming the beliefs one already has, and to generally conduct one's inquiries in ways likely to reinforce, rather than undermine, one's prior opinions 10 This isn't entirely adequate as a characterization of a form of bias, where that is construed as a pejorative. Some form of methodological conservatism is widely viewed as good epistemic practice; extraordinary claims require extraordinary evidence, and sometimes it can be quite appropriate, when faced with phenomena that provide a prima facie challenge to a firmly entrenched view, to look for ways of interpreting those phenomena so that they fit with the firmly entrenched view 11 But for present purposes we can set aside the problem of distinguishing confirmation bias from sensible conservatism; for now, the question is why, or whether, we should think cultural cognition as anything other than a tendency to stick to one's preexisting beliefs, even in the face of apparent counterevidence.

After all, the subjects in Kahan et al. (2011) likely had prior views about the effectiveness of gun control, the riskiness of climate change, the safety of nuclear waste disposal, etc. If you're faced with evidence that a putative expert rejects the views you currently hold, but because you're subject to confirmation bias you'll try to interpret new evidence in ways unthreatening to the views you already hold, then deciding that this "expert" is in fact no such thing is a natural response ${ }^{12}$ Kahan (Forthcoming) considers this response, and takes pains to explain how a cultural cognizer will reason differently from a victim of confirmation bias. Roughly, the idea is as follows. If confirmation bias

conclusion.

${ }^{10}$ See (Kahneman, 2011, Part 1, §7) for discussion.

${ }^{11}$ This idea is often associated with Kuhn (1962).

${ }^{12}$ See, e.g., Sunstein (2006) who argues that "cultural cognition" is explicable entirely in terms of the familiar set of phenomena known as "bounded rationality", of which confirmation bias is a prominent example. Kahan and Slovic (2006) reply directly, but the more relevant aspect of the response for present purposes is discussed in Kahan (Forthcoming). 


\section{Climate Change and Cultural Cognition}

is what explains the results above, then we should expect it will be very hard to change people's minds about, e.g., the riskiness of global warming. Once someone has an opinion, they'll interpret all further evidence so as to reinforce, or at least not undercut, that opinion. But if cultural cognition is what's responsible, then there is a potential path to persuasion. If the "cultural meaning" of an opinion can be manipulated - if subjects can be provided with information that makes the opinion seem more congenial to their cultural worldview than it previously did - then it should be possible to change their minds.

This is just what Kahan et al. (2015) found evidence for. In their study, subjects read a "Nature Science" article - presented as a stand-alone publication, but in fact composed of passages from genuine papers in Nature and Science-describing various risks associated with climate change, though not advocating for any particular policy response to those risks. The general thrust of the piece was bleak; it stated that even with "strenuous efforts to reduce emissions, atmospheric $\mathrm{CO}_{2}$ concentrations will rise beyond 450 ppm, the level commonly thought to be the maximum safe limit." Before reading the article, however, they read one of three different pieces - two framed as responses to the Nature Science study, and a control piece on an unrelated topic. One response called for stricter limits on carbon emissions, while the other called for greater investment in geoengineering research as an alternative to stricter emissions limits. Subjects then answered various questions about their opinions of the validity of the Nature Science study, as well as the risks of climate change more generally. Kahan et. al's hypothesis was that, depending on subjects' cultural worldviews - measured on two scales, from individualist to communitarian and hierarchical to egalitarian - they'd respond to the experimental manipulation differently. In particular, subjects with hierarchical individualist worldviews tend to have very different attitudes towards commerce and industry than subjects with egalitarian communitarian worldviews. Hierarchical individualists tend to value commerce, and to be skeptical of legal restrictions on commercial activi- 


\section{Climate Change and Cultural Cognition}

ties. Egalitarian communitarians, by contrast, "see commerce and industry as sources of unjust disparity and symbols of noxious self-seeking, and thus readily credit assertions that these activities are hazardous and therefore worthy of regulation." Kahan et al., 2015, p.194) To the extent that the cultural meaning of the Nature Science study is that it favors more limits on commerce and industry — as subjects who read the response piece advocating for stricter emissions caps will feel-hierarchical individualists should tend to be suspicious, while egalitarian communitarians should tend to be sympathetic ${ }^{13}$

But if hierarchical individualists interpret the cultural meaning of the Nature Science study differently — which was the purpose of their reading the geoengineering piece - then they might be less resistant to crediting it. As Kahan et. al. explain:

Researchers who study the impact of narrative on cultural cognition posit that hierarchical individualists assess information against a story template that valorizes the use of human ingenuity to overcome seeming natural limits on commerce and industry (Jones 2014; Earle and Cvetkovich 1995). By featuring how an innovative technology might itself be used to offset the damaging byproducts of technological innovations on the environment, geoengineering, we posited, would evoke this theme and related affective sensibilities. (p. 200)

Sure enough, after reading the geoengineering response piece, hierarchical individualists were significantly more likely to credit the Nature Science article about risks of climate change than after reading the emissions limits response piece 14 Perhaps surprisingly, this effect was symmetrical - after reading the geoengineering response piece, egalitarian communitarians were significantly less likely to credit the Nature Science article than after reading the emissions limits response piece. All this would be difficult

\footnotetext{
${ }^{13}$ Of course, there are also hierarchical communitarians, and egalitarian individualists. Their responses didn't contrast as sharply with one another as did those of the hierarchical individualists and egalitarian communitarians, though.

${ }^{14}$ Though they still credited the article a lot less than egalitarian communitarians did.
} 


\section{Climate Change and Cultural Cognition}

to explain, Kahan argues, if it were just confirmation bias at work (Forthcoming). Individuals subject to confirmation bias would form firm opinions about climate change and would then resist changes to those opinions, whether prompted by additional evidence of a familiar sort, or exposure to the sorts of response pieces involved in Kahan et. al.'s study. The fact that exposure to those responses did prompt people to modify their opinions suggests that confirmation bias isn't the whole story.

Before moving on, let's take stock. Part of my aim in summarizing the above research was to draw attention to a partial answer to the descriptive question of how we decide whom to trust on controversial matters of political import-we use cultural cognition. But I also hope it makes salient the trickiness of related normative questions. In particular, to the extent that (a) there are controversial factual questions about the efficacy of geoengineering proposals and the danger of their side effects, and (b) our views about whom to trust on these matters matter are likely shaped by cultural cognition 15 it's natural to start asking normative questions about the rationality of cultural cognition. If we have strong initial reactions to geoengineering proposals - as a non-trivial proportion of the public does when exposed to them (Mercer et al., 2011) - should we distrust those reactions, once we get evidence that they were likely shaped in this way?

To shed some light on this question, I'll start by pushing back on Kahan's argument that cultural cognition can be cleanly distinguished from confirmation bias. Having done that, I'll go on to argue that, at least in the relevant cases, it's also hard to distinguish cultural cognition from from simple Bayesian updating, with certain sorts of priors.

\footnotetext{
${ }^{15}$ To be clear, I don't know of any studies that directly look for relations between cultural worldviews and opinions on geoengineering- Kahan et al. (2015) never directly asks people their opinions on geoengineering, and while Mercer et al. (2011) provides helpful evidence concerning public opinions on geoengineering, they don't look at the relationship between those opinions and the cultural worldviews that figure in Kahan's line of research.

${ }^{16}$ Perhaps, e.g., for reasons of the sort discussed by Ballantyne $(2012)$ and Vavova $(2016)$.
} 


\section{Climate Change and Cultural Cognition}

\section{$3 \quad$ Values or Beliefs?}

For reasons already explained, Kahan (Forthcoming) makes a compelling case that certain form of confirmation bias - a bias towards maintaining one's opinion about the validity of studies suggesting serious risks from climate change - cannot explain the phenomena described in Kahan et al. (2015).

But it would be too quick to conclude from this that such phenomena cannot be explained by any form of confirmation bias. Suppose we think of the subjects as predisposed towards maintaining not their specific beliefs about climate change risks, but their more general beliefs about cultural groups and trustworthiness. How might this more general disposition explain the behavior of the subjects in the study? Suppose hierarchical individualists tend to distrust environmentalists - i.e., they think that environmentalists tend to be wrong about the factual issues on which they take distinctive positions. This distrust will lead them, upon reading about how environmentalists take climate change risks seriously, to take those risks less seriously. But when reading that geoengineering advocates take climate change risks seriously, we might naturally expect the opposite reaction. Geoengineering - especially as presented in the study in Kahan et al. (2015), with pictures of giant carbon scrubbers being erected in an otherwise pristine wilderness, and futuristic aircraft spraying chemicals into clouds - seems like exactly the sort of policy that environmentalists would hate. So when hierarchical individualists learn that among those who take climate change seriously are people who are not culturally associated with environmentalists - indeed, people who propose measures of the sort environmentalists reject - they get reason to take climate change more seriously themselves. And the opposite will hold for egalitarian communitarians. Once they learn that among the people who take climate change seriously are people who would propose such prima facie anti-environmentalist measures, they take climate change (a bit) less seriously themselves. 


\section{Climate Change and Cultural Cognition}

The crucial point here is that, on the above interpretation, the phenomena are explained as a consequence of well-entrenched beliefs; values needn't be playing a fundamental cognitive role. Kahan et al. (2015) isn't the only study to which Kahan (Forthcoming) appeals to distinguish confirmation bias from cultural cognition. But other studies are vulnerable to a similar reinterpretive strategy. For example, in Kahan et al. (2012), in a between-subjects design, subjects saw a video that they were either told was of an anti-abortion protest outside an abortion clinic, or a protest against the "don't ask, don't tell" policy, outside a campus recruitment center. They were then asked questions about whether the protesters "blocked" and "screamed in the face" of pedestrians, and more generally whether the protesters' conduct was aimed only at persuasion, or instead intimidation. Subjects' responses were significantly mediated by their cultural worldviews. E.g., hierarchical individualists were significantly more likely to see "blocking" when the protest was supposedly outside a military recruitment center than when it was outside an abortion clinic ( $83 \%$ vs. $62 \%$ ). Egalitarian communitarians displayed the opposite pattern, seeing more blocking outside the abortion clinic (56\% vs $35 \%)$. (p. 29)

Kahan (Forthcoming) argues that these results cannot be explained as the result of overly sticky beliefs (confirmation bias), because the beliefs in question were an artifact of the experiment, and didn't even exist prior to it - before they saw the video, subjects had no views about the (fictional) protest, or the conduct of the demonstrators therein. But subjects did, presumably, have general beliefs about behavioral tendencies of members of cultural groups, which might have influenced the specific beliefs about the protesters they went on to form. Suppose, plausibly, hierarchical individualists think that antimilitary protesters tend to be unruly and rude, while anti-abortion protesters tend to be fervent, but respectful. And suppose egalitarian communitarians think that antiabortion protesters tend to be heartless and judgmental, while anti-military protesters tend to be passionate, but peaceful. Then after watching a three and a half minute 


\section{Climate Change and Cultural Cognition}

video, we might expect that these standing views would influence subjects' recollection and interpretation of ambiguous visual evidence 17 Just how this influence might work is a complex, and much-studied topic ${ }^{18}$ But what matters is that, on this interpretation, values enter into the picture only in a derivative way; the phenomena are explained by subjects' general beliefs about how people with values that differ or align with their own tend to behave.

I've just argued that grounds Kahan (forthcoming) offers to think that the phenomena he and his coauthors have identified cannot be explained by confirmation bias are inadequate. But in fact, the response is more general - nothing in my response depends on the idea that the general beliefs that play a role in explaining such phenomena be biased in some normatively loaded sense. Given an orthodox subjective Bayesian view, hierarchical individualists might be perfectly rational in harboring a general distrust of environmentalists, just as cultural egalitarians might be perfectly in trusting them 19 Even given more objective views, at least some of these general beliefs about which groups are trustworthy might be rational, even if not all will be. Once we think of these phenomena as potentially explained by straightforward updating on general beliefs, rather than by some cognitively distinctive process in which values are usurping the roles typically reserved for beliefs, should we continue talking about some distinctive species of "cultural cognition", and asking questions about its normative status? In the next section I'll explore some reasons to think the answer might still be "yes".

\footnotetext{
${ }^{17}$ On the point about ambiguity, there was relatively less polarization on more clear-cut questions such as whether protesters spat or shoved pedestrians (p. 29).

${ }^{18}$ In particular, given a strong "cognitive penetrability" thesis, subjects' background cognitive states, such as beliefs about who tends to be rude or violent, might directly effect their visual experiences upon seeing a video like the one in the study. While such theses have been widely endorsed, there are some strong grounds for skepticism - see Firestone and Scholl (2015). But even skeptics of strong cognitive penetrability theses grant that background cognitive states often modulate attention, in ways that have significant influences on perceptual judgments and recollections of those judgments.

${ }^{19}$ See Howson and Urbach (1996) for a canonical defense of this view.
} 


\section{Cultural Cognition and Coincidence}

The core idea of cultural cognition is that it involves values taking some sort of cognitive priority over beliefs. In the previous section I explored how, in the explanations Kahan offers, general beliefs could take the place of values, apparently depriving values of any cognitively distinctive (and potentially suspicious) role to play. In this section, however, I'll try to make a case that even if this is right, the sort of general beliefs involved might nevertheless be an appropriate target of normative criticism, due to a kind of dependence on values.

To see why, it may help to return to (putative) examples of cultural cognition that directly involve views about public policy, rather than whom to trust about public policy. For example, recall how those whose values oppose (favor) the death penalty tend to believe it lacks (has) a significant deterrent effect, or the analogous relation between holding values congenial or hostile to gun ownership, and beliefs about consequences of concealed carry laws ${ }^{20}$ These correlations seem (to me at least, and I hope to the reader) like plausible symptoms of some kind of irrationality; to the extent that I notice such correlations in my own body of belief, I get worried, and suspect that I've succumbed to some sort of bias. Why should this be? A natural thought is that, to the extent that this pattern holds quite generally for a subject - that whichever policies she favors on basic values grounds, she also thinks have independently good consequences - this should seem, from the subject's point of view, like a striking, unexplained coincidence. Suppose the death penalty is both fundamentally unjust, and applied in a racially discriminatory manner ${ }^{21}$ Neither of these properties would plausibly figure, however, in any explanation of its deterrent effects; if it lacks a significant deterrent effect, the explanation for that absence won't have to do with its fundamental injustice, or its racially discriminatory application 22 So if one believes both that it is fundamentally unjust and applied in a

\footnotetext{
${ }^{20}$ On the former, see Kahan $(1999)$. On the latter, see Kahan et al. $(2011)$.

${ }^{21}$ See, e.g., Baldus et al. (1997).

${ }^{22}$ This is a bit quick. E.g., if the death penalty is never applied to members of some racial group, and
} 


\section{Climate Change and Cultural Cognition}

discriminatory manner, and that it lacks a deterrent effect, one believes a coincidence.

In the remainder of this section, I'll argue as follows. First, I'll offer a (rough) analysis of the notion of a coincidence. Then, with this analysis in hand, I'll argue that (1) the general beliefs that would figure in explaining cultural cognition would typically be beliefs in coincidences, and (2) there's an important sense in which beliefs in coincidences are epistemically suspect.

I'll take the following as a working analysis of the notion of coincidence: P \& Q is a coincidence if the best explanation of $\mathrm{P} \& \mathrm{Q}$ is just the best explanation of $\mathrm{P}$, concatenated with the best explanation of ${ }^{23}$ It's not particularly important to me that this capture all cases we'd tend to characterize as coincidences-my aim is just to be able to identify a target notion of coincidence for which both (1) and (2) above hold. But I do want to say a bit about why it might seem like a natural analysis, by taking a paradigm coincidence, and a paradigm non-coincidence, and showing how the analysis neatly fits them both. First, let's take a paradigm coincidence. Suppose I run into two whiskey distillers on the same day. Two versions of the case:

1. They're in town for independent reasons; one of them is visiting a relative who just had a child, while the other is here to watch a sporting event.

2. They're both in town for the American Craft Spirits Association (ACSA) convention, and I meet them in the convention hotel. ${ }^{24}$

Case 1 clearly describes a coincidence. The analysis captures this. We can formulate the target coincidence as a conjunction: I met A, who is a whiskey distiller, and I met B, who is a whiskey distiller. And the explanation of this conjunction will

this is widely known, then we should expect that it wouldn't deter crime among members of that group.

${ }^{23}$ This is very much in the spirit of Owens (1992), who defends the view that for a conjunction to be a coincidence is for the conjuncts to lack a common cause. While my emphasis is different, it's quite plausible that when events have a common cause, the best explanation of their conjunction will feature that common cause, and so will be more concise than a concatenation of their best explanations, individually. While there are problems with this account - see Lando (2016) for some ingenious counterexamples, as well as a plausible diagnosis of the problem-it's close enough for present purposes.

${ }^{24} \mathrm{~A}$ true story of my experience at the 2016 central APA. 


\section{Climate Change and Cultural Cognition}

just be the concatenation of the explanation of my meeting $A$, and the explanation of my meeting B. Case 2 clearly describes a non-coincidence. The analysis captures the contrast. In case 2 , the best explanation of the conjunction won't concatenate the best explanations of the conjuncts, since that would involve unnecessary repetition. The best explanation of the first conjunct overlaps substantially with the best explanation of the second conjunct - both explanations crucially involve the ACSA convention ${ }^{25}$ Since good explanations aren't needlessly redundant, the best explanation of the conjunction would only say once, rather than twice, that the convention was in town.

Why should we be worried about believing coincidences? In general, we shouldn't. E.g., if I know there is no ACSA convention in town, or anything else that would tend to attract distillers, and yet I still meet two distillers on the same day, there needn't be anything wrong with believing this to be a coincidence. Nevertheless, there is a special sort of case in which beliefs in coincidences are epistemically suspect. Suppose a subject $\mathrm{S}$ believes $\mathrm{P} \& \mathrm{Q}$, and takes this to be a coincidence. But suppose, in addition, that the conjunction $\mathbf{S}$ believes $\mathbf{P} \& \mathbf{S}$ believes $\mathbf{Q}$ is itself not a coincidence; that is, the explanation of why $\mathrm{S}$ believes both $\mathrm{P} \& \mathrm{Q}$ is better than what you'd get by just tacking an explanation of why $\mathrm{S}$ believes $\mathrm{P}$ onto an explanation of why $\mathrm{S}$ believes $\mathrm{Q}$. To the extent that one suspects one is such a subject, one has reason to suspect one has succumbed to some form of bias or irrationality.

The preceding was somewhat abstract, so it may help to consider an example. Suppose Don is prejudiced against Armenians, in the sense that he tends to form negative judgments of individual Armenians he meets. But suppose he doesn't have any negative general beliefs about Armenians as a group. So Don believes, e.g., that Georgy is dishonest and that Houry is incompetent, but doesn't think there's any common explanation of these facts - he takes this conjunction to be a coincidence. Nevertheless,

\footnotetext{
${ }^{25} \mathrm{~A}$ more careful analysis would probably focus on degrees of coincidence. The greater the overlap in the best explanations of the conjuncts, the less coincidental the conjunction. Even case 1 would involve some overlap, and so wouldn't be maximally coincidental. But for present purposes, we can harmlessly treat the notion of coincidence is a binary one, for the sake of simplicity.
} 


\section{Climate Change and Cultural Cognition}

the fact that he believes both of these things is not a coincidence - the best explanation for this conjunction is that Don tends to form negative beliefs about Armenians, and Georgy and Houry are both Armenian 26 The epistemically problematic cases of beliefs in coincidences, that is, are cases where there's no common explanation of the (putative) facts that $\mathrm{P}$ and that $\mathrm{Q}$, but there is a common explanation of a subject's belief in those facts.

Why should such cases, in general, be symptomatic of irrationality? In general, we hope that patterns in our beliefs will correspond to patterns in the facts those beliefs are about. To the extent that they don't, our beliefs are inappropriately unresponsive to reality, and will be inaccurate. When we have evidence that patterns in our beliefs are unrelated to patterns in reality - that the explanations for why we believe what we do are unrelated to the explanations for why the facts are the way they are - we have evidence that our beliefs are inaccurate, which should force some kind of reassessment of those beliefs. It's hard to extend these sketchy remarks into a fully general rule or test for irrationality. For instance, the principle that we should only believe those propositions that play a role in explaining why we have the beliefs we do, is self-defeating ${ }^{27}$ But we needn't endorse any such fully general thesis to think that, for ordinary, nonfoundational, empirical beliefs, it's some kind of red flag when the best explanation of the belief is unrelated to the best explanation of the (putative) fact it's a belief about.

Let's return to cultural cognition, as we're now in a position to state more precisely what sort of epistemological worries it raises. A cultural cognizer believes some normative claim $\mathrm{P}$, and some descriptive claim $\mathrm{Q}$, such that $\mathrm{P} \& \mathrm{Q}$, if true, would be a coincidence ${ }^{28}$ But there are available various plausible, non-coincidental explanations for why she believes both P \& Q - perhaps involving wishful thinking, or cognitive dis-

\footnotetext{
${ }^{26}$ So by the analysis, an explanation of the conjunction that concatenated the explanations for the conjuncts would be needlessly repetitive, in that it would mention Don's prejudice twice.

${ }^{27}$ See Pust (2001), who attributes similar theses to Gilbert Harman and Alvin Goldman and argues, convincingly to my mind, that the theses are self-defeating when endorsed in full generality.

${ }^{28}$ There are also cases where both claims are descriptive, but the paradigm cases will involve normative and descriptive claims.
} 


\section{Climate Change and Cultural Cognition}

sonance reduction, or other related psychological mechanisms. To the extent that the cultural cognizer comes to appreciate her situation, some kind of reassessment is called for - she has evidence that there are patterns in her beliefs that are unrelated to patterns in reality.

What about when the beliefs at stake aren't directly about the consequences of public policies, but instead about whom to trust concerning those consequences? Can this sort of cultural cognition also be understood as involving belief in potentially suspicious coincidences? I think it can. The two potentially coincidental sorts of beliefs will be as follows. First, beliefs to the effect that certain putative experts' values are the right (wrong) ones concerning the area of policy in question. Second, beliefs to the effect that those putative experts are reliable (unreliable) about descriptive questions concerning the consequences of policies in the relevant area.

I don't mean to imply that such combinations of belief would always be beliefs in coincidences. It's plausible that, in some cases, there will be common explanations of people's reliability on evaluative matters, and on factual matters. For example, a capacity for empathy might both enable someone to appreciate certain moral facts (e.g., concerning others' dignity, entitlement to respect, moral status, etc.), and certain non-moral facts (e.g., concerning others' psychological states) ${ }^{29}$ But such connections shouldn’t be treated as a default; in the absence of some explanation as to why moral and non-moral reliability in an area should coincide, we should treat their putative coincidence as, well, coincidental ${ }^{30}$ And insofar as we find ourselves consistently and across domains thinking that those with the right values are also the most reliable on descriptive questions, we should worry that we've succumbed to some form of irrationality—we'll have noticed

\footnotetext{
${ }^{29}$ Though see Bloom (2016).

${ }^{30}$ Street (2006) argues that while there are available good evolutionary explanations of our reliability on non-moral matters, our reliability on moral matters would be inexplicable, in the absence of a constructivist metaethics. And even in the presence of such a metaethics, our reliability on moral matters receives a very different explanation than our reliability on non-moral matters. I mention her position not to endorse it, but just to make salient that the task of explaining our reliability on non-moral matters may look very different from explaining our reliability on moral matters.
} 


\section{Climate Change and Cultural Cognition}

a pattern in our beliefs that doesn't plausibly match a pattern in reality.

This diagnosis neatly fits some cases of cultural cognition, but other cases are less obvious, and some don't fit at all. To see how, it will help to contrast two cases. Imagine two individuals, both of whom have broadly libertarian values - they oppose most economic regulations. They also both believe that economic regulations tend to stifle innovation and to increase poverty - they tend to produce changes that even non-libertarians would recognize as for the worse. Our first libertarian, however, holds her position for fundamentally deontological reasons - she believes that, irrespective of their downstream consequences, economic regulations infringe on people's rights, and are intrinsically wrong. Perhaps she was convinced by Nozick (1974). Our second, by contrast, has purely consequentialist, non-rights-based grounds for her libertarianism. Now, imagine both of them are confronted with some new proposed regulation. Both of them think it would be wrong to enact, and both of them think it would have bad consequences. If my earlier claims are right, our first libertarian has grounds for suspicion about her beliefs. By her lights, the fact that economic regulations are both unjust and have bad consequences is a pure coincidence. The discussion above suggests that her beliefs deserve serious scrutiny, even if they may survive it. But by contrast, our second libertarian needn't countenance any such suspicious coincidence; while she thinks that economic regulations are unjust, and that they have bad consequences, the former fact is fully grounded in the latter. There's nothing epistemically suspicious here 31 Both subjects would probably look like cultural cognizers in a social scientific survey; they'd both assent to general statements like "People who are successful in business have a right to enjoy their wealth as they see fit," and "Government regulations are almost always a waste of everyone's time and money, ${ }^{32}$ and would both also agree to claims about how particular regulations would likely have undesirable consequences. But these similarities

\footnotetext{
${ }^{31}$ I'm setting aside, of course, questions about what the evidence actually suggests concerning consequences of economic regulations.

${ }^{32}$ These are items from the worldview scales used by Kahan and collaborators. See http://www.sjdm. org/dmidi/Cultural_Cognition_Worldview_Scales.html.
} 


\section{Climate Change and Cultural Cognition}

conceal crucial epistemological differences.

Does this mean that cultural cognition only raises epistemological worries in cases where the "values" in question that correlate with beliefs are genuinely values, rather than relatively general factual beliefs about what sorts of policies have what sorts of consequences? I don't think so. Even in the latter case, essentially the same kinds of worries about suspicious coincidences can arise. An example may help make this clear. Suppose a political party releases a platform detailing many positions on a wide range of issues - economic policy, foreign policy, social policy, science policy, etc.. Suppose, plausibly, that there is no simple rationale that would collectively justify each of these positions - after all, they're positions on widely disparate issues. Rather, if they are each good policies, they are good policies for almost entirely independent reasons. Now imagine someone who's always voted for this party, call him "Team Player". who thinks that each of the policies in the platform is a good one, in the sense that each policy would in fact have consequences that are widely recognized as desirable (i.e., even by people of conflicting worldviews). There is at least the threat of suspicious coincidence here. Even though each of the beliefs in this case-beliefs about the likely effects of some or another policy — is strictly factual, their joint truth might look suspiciously coincidental, by Team Player's lights. Certainly this will be true if Team Player doesn't think that the process by which the party platform was generated was particularly reliable - in that case, the situation would be like somebody winning the lottery many times in a row: suspicious. But even if Team Player does think the process by which the party platform was generated was reliable, that belief might itself look like a belief in a coincidence. After all, since the party platform concerned so many diverse areas of policy, the party would have to have reliable methods for discerning facts across unrelated domains, and would have to reliably pick the policies best supported by those facts across diverse domains. While this certainly isn't impossible, it's the sort of thing that should make Team Player wonder - how is it that my party so consistently got things right? And to 


\section{Climate Change and Cultural Cognition}

the extent that Team Player cannot come up with a good answer here, he should worry that this pattern in his beliefs - his consistently thinking that his side got things rightis produced by some kind of bias, rather than an appreciation of a genuine pattern in reality.

\section{5}

How should these general lessons inform our thinking about climate change and geoengineering? My aim in this section will be as follows. First, I'll provide a very brief summary of the range of opinion on the promises and risks of geoengineering. Then, I'll contrast how an unreconstructed cultural cognizer would react to these facts, with how we should react to them after learning to be skeptical of beliefs formed via cultural cognition.

While there is a great deal of evidence about opinions - both scientific and layconcerning general questions about the existence of anthropogenic global warming, there is relatively less evidence about the distribution of opinion on geoengineering. Moreover, in the case of lay opinion, responses differ significantly depending on how questions are framed-perhaps unsurprisingly, given the relative lack of public familiarity with geoengineering 33

Both the Royal Society (2009) and the National Academies of Sciences, Engineering, and Medicine (2015) have released reports that provide evidence of some points of scientific consensus. First, geoengineering shouldn’t be seen as an alternative to emissions reductions - at best, it would be a supplement. Second, no geoengineering proposals are

\footnotetext{
${ }^{33}$ Compare the results reported in Mercer et al. (2011), which show a decent amount of support for geoengineering (or at least, for geoengineering research), with those of the National Survey of American Public Opinion on Climate Change - the relevant portions of which are summarized by Borick and Rabe (2012) - which seem to show more skepticism. While the surveys were taken at similar times by similar populations, the exact questions asked were different. Moreover, Mercer et al. (2011) included information explaining the concept of solar radiation management - a particular version of geoengineering — while the National Survey of American Public Opinion on Climate Change did not.
} 


\section{Climate Change and Cultural Cognition}

well enough understood yet for implementation on a wide scale. Both reports call for additional research, both scientific - e.g., concerning the feasibility and risks of various geoengineering proposals - and political - e.g., concerning how geoengineering proposals might be agreed upon and subsequently regulated on an international scale. But even if there is agreement on those points - and there's some reason to think that even the call for more research is controversial - it likely conceals a wide range of attitudes, ranging from the very pessimistic to the cautiously optimistic, about the promise of geoengineering ${ }^{34}$

While no major scientific body endorses either pole of pessimism or optimisim about geoengineering, other groups have taken much stronger positions, both pro and con. The American Enterprise Institute (AEI) - a conservative think tank - launched a geoengineering project. While the AEI doesn't adopt official positions on policy issues, it's fair to say that the project was generally pro-geoengineering. For example, it was co-directed by Lee Lane, who testified before the House Select Committee for Energy Independence and Global Warming that "research to learn more about geoengineering's potential and limitations might be one of the very best ways of hedging against the larger risks and uncertainties that surround climate policy." (2008) On the other side, the Action Group on Erosion, Technology, and Concentration (more commonly known as the "ETC Group") has launched an anti-geoengineering campaign called Hands Off Mother Earth (HOME), opposing not only full-scale deployment, but also preliminary testing of any geoengineering technologies 35

What will a cultural cognizer, upon learning the above, think about geoengineering?

\footnotetext{
${ }^{34}$ I don't know of any large scale survey of scientific opinion on geoengineering, though in 2009 the UK's Independent conducted a poll of 80 leading scientists, finding that $54 \%$ agreed with the need for a geoengineering-based "plan B" in case efforts to reduce emissions fail, while $35 \%$ disagreed, and $11 \%$ said they didn't know whether such a plan was necessary (Green and Connor, 2009). See the online debate between Keith and Hulme (2013) for representatives of these two poles.

${ }^{35}$ I don't mean to imply that environmental groups have spoken with one voice. See the website below for a summary of the positions of the Environmental Defense Fund and those of other groups; the ETC group's opposition is the strongest, with the Environmental Defense Fund and many other groups calling for small-scale experimentation with geoengineering techniques: https://www.edf.org/climate/ourposition-geoengineering.
} 


\section{Climate Change and Cultural Cognition}

One possibility, suggested by the results reported in Kahan et al. (2015), is that geoengineering all on its own - independent of facts about the distribution of opinion about it - would trigger cultural associations, depending on one's values either positive or negative. But even in the absence of such associations, knowing that institutions like the AEI and the ETC group stand on opposite sides of the issue would likely be enough to imbue it with a cultural valence, either positive or negative depending on one's antecedent sympathies and antipathies for conservative pro-business groups and environmentalist groups. Hierarchical individualists, then, seeing that groups they trust (because of their generally free market stance) support geoengineering, and that groups they distrust (because of support for limits on free enterprise and entrepreneurial culture) oppose it, will tend to support geoengineering. Faced with disagreement among leading scientists, they'll likely modify their opinions of which scientists are really experts - taking those optimistic about geoengineering to be more qualified and knowledgable than those pessimistic. And we would expert a symmetrical and opposite reaction from egalitarian communitarians, resulting in their discrediting those scientists who are optimistic about geoengineering, and trusting those more skeptical 36

But what if we've learned to distrust cultural cognition? Whatever our values, we'll be hesitant to treat those who share (reject) our values as thereby reliable (anti-reliable) on factual questions. So, whether we share the values of the AEI or not, we won't think that they are thereby reliable or anti-reliable on questions about the magnitude of the risks and benefits of geoengineering. Likewise with the ETC group. Moreover, since neither the AEI nor the ETC group have many expert climate scientists as members-where expertise is judged on the largely culturally neutral grounds of the sort discussed by Anderson (2011), involving things like advanced degrees, publication in leading journals, membership in honorary scientific societies, and the like - we won't take their positions to have a great deal of evidential weight concerning factual questions about the risks

\footnotetext{
${ }^{36}$ This would be the same dynamic as the one reported in Kahan et al. (2011).
} 


\section{Climate Change and Cultural Cognition}

and promises of geoengineering proposals.

We will take the reports like that of the Royal Society and the National Academy of Sciences very seriously. But as already discussed, both reports are quite cautious, and neither endorses a strong position on geoengineering - either optimistic or pessimisticthat we might adopt as our own. While the reports of those two bodies likely reflect internal disagreement among their members, unlike the unreconstructed cultural cognizer we'll lack anything we recognize as good grounds for deciding, among those members, which ones are more reliable and trustworthy than others; we won't be able to identify the more optimistic or pessimistic members as the genuine experts. So we'll likely end up quite uncertain about the risks and rewards of geoengineering-hoping for more research, but uncertain which (if any) geoengineering proposals will be advisable once such research is conducted.

This isn't to say that we'll regard the cultural associations of geoengineering as completely irrelevant to questions about its risks. Insofar as a potential partial explanation for the AEI's support for geoengineering is that they hope it will undermine support for strict emissions limits, and insofar as we agree with the aforementioned reports that strict emissions limits are necessary (regardless of whether geoengineering is or is not pursued), we may acknowledge a political risk of geoengineering to which its cultural associations are relevant. But we shouldn't be confident about the magnitude of this political risk. Recall the results from Kahan et al. (2015), in which hierarchical individualists were less skeptical about research warning of harms from AGW after reading about geoengineering. It's entirely possible that widespread discussion of geoengineering might increase support for strict emissions limits, by undermining the sense among AGW skeptics that climate change is a "hoax" cooked up merely to motivate such limits. Absent further similar research, confidence about whether geoengineering research would distract from political action on emissions is unwarranted. 


\section{Climate Change and Cultural Cognition}

\section{Conclusion}

My aim in this essay has been to explore the epistemological implications of a psychological thesis about how we decide whom to trust concerning matters of cultural and political significance. While I've used the examples of climate change and geoengineering to frame my discussion, the lessons are, I hope, much broader.

Much has been written recently on the epistemology of disagreement 37 While a good deal of the discussion has focused on disagreement between "epistemic peers" roughly, people in an equally good position to get at the truth on some matter-there's something a bit odd about this ${ }^{38}$ After all, in many of the most pressing, real-life cases, including that of geoengineering, the disagreement that seems most significant is disagreement between our epistemic superiors. And whatever the plausibility of the idea that some kind of agnosticism or conciliatory response is called for when you find yourself disagreeing with your epistemic peer, it's significantly more plausible that such responses are called for when you find your epistemic superiors disagreeing with each other.

But just how common should we think it is that, on descriptive questions about the likely consequences of public policy, there is little consensus among our epistemic superiors? 39 How we answer this question will likely depend on whether we're comfortable using cultural cognition to decide who counts as an expert. If we're unreconstructed cultural cognizers, we'll find relatively more agreement among those we take to be experts - because we will withhold the status of "expert" from those who don't share our values - and we'll therefore have an easier time identifying and deferring to a robust expert consensus. But if we're skeptical about cultural cognition and manage to stop

\footnotetext{
${ }^{37}$ For a sampling, see the papers collected in Feldman and Warfield (2010) and Lackey and Christensen (2013).

${ }^{30}$ This isn't to say that all of the literature focuses on peer disagreement. See, e.g., Goldman (2001), Frances (2010), Ballantyne (2014) for some examples of papers broadly in the disagreement literature, but which focus on the challenge posed by disagreement from epistemic superiors.

${ }^{39}$ See the discussion of "spinelessness" in Elga (2007) to get a sense for some of the complexities here.
} 


\section{Climate Change and Cultural Cognition}

ourselves from using it, the pool of people we count as "experts" will be wider, and the opinions in that pool will tend to be more varied. We'll have a harder time making our way to firm views about the likely consequences of controversial public policies.

Much psychological research suggests that refraining from using cultural cognition should be difficult and unpleasant; strong opinions about controversial questions of public policy are markers of group membership and cultural identity, and if we shed them, we may feel as if we are shedding our very selves. I say, so be it! Where is it written that rationality should be easy?

\section{Bibliography}

2009. Geoengineering the Climate: Science, Governance, and Uncertainty, Royal Society Policy Document 10/09. The Royal Society.

2015. Climate Intervention: Carbon Dioxide Removal and Reliable Sequestration and Climate Intervention: Solar Radiation Management. National Academies Press.

Anderson, Elizabeth. 2011. "Democracy, Public Policy, and Lay Assessments of Scientific Testimony." Episteme 8:144-164.

Baldus, David, George Woodworth, David Zuckerman, Neil Alan Weiner, and Barbara Broffitt. 1997. "Racial Discrimination and the Death Penalty in the Post-Furman Era: An Empirical an dLegal Overview with Recent Findings from Philadelphia." Cornell Law Review .

Ballantyne, Nathan, 2012. "The Problem of Historical Variability." In Machuca, Diego, editor, "Disagreement and Skepticism," Routledge.

. 2014. "Counterfactual Philosophers." Philosophy and Phenomenological Research 87:368-387. 
Bloom, Paul, 2016. Against Empathy. Harper Collins.

Borick, Christopher, and Gary Rabe, 2012. "Americans Cool on Geoengineering Approaches to Addressing Climate Change." Issues in Governance Studies (A Publication of the Brookings Institution).

Coady, C. A. J., 1992. Testimony: A Philosophical Study. Oxford University Press.

Elga, Adam. 2007. "Reflection and Disagreement." Nous 41:478-502.

Feldman, Richard, and Ted Warfield, editors, 2010. Disagreement. Oxford University Press.

Firestone, Chaz, and Brian Scholl. 2015. "Cognition does not affect perception: Evaluating the evidence for 'top-down' effects." Behavioral and Brain Sciences .

Frances, Bryan. 2010. "The Reflective Epistemic Renegade." Philosophy and Phenomenological Research 81:419-463.

Goldman, Alvin I. 2001. "Experts: Which Ones Should You Trust?" Philosophy and Phenomenological Research 63:85-110.

Green, Chris, and Steve Connor. 2009. "Climate scientists: it's time for 'Plan B': Poll of international experts by The Independent reveals consensus that $\mathrm{CO} 2$ cuts have failed-and their growing support for technological intervention." The Independent .

Howson, Colin, and Peter Urbach, 1996. Scientific Reasoning: The Bayesian Approach. Open Court.

Jost, John. 2015. "RESISTANCE TO CHANGE: A SOCIAL PSYCHOLOGICAL PERSPECTIVE." Social Research .

Kahan, Dan. 1999. "The Secret Ambition of Deterrence." Harvard Law Review . 


\section{Climate Change and Cultural Cognition}

—. Forthcoming. "The Politically Motivated Reasoning Paradigm." Emerging Trends in Social \& Behavioral Sciences .

Kahan, Dan, and Donald Braman. 2006. "Cultural Cognition and Public Policy." Yale Law and Policy Review .

Kahan, Dan, David Hoffman, Donald Braman, Daniel Evans, and Jeffrey Rachlinski. 2012. " "They Saw a Protest": Cognitive Illiberalism and the Speech-Conduct Distinction." Stanford Law Review .

Kahan, Dan, Hank Jenkins-Smith, and Donald Braman. 2011. "Cultural Cognition of Scientific Consensus." Journal of Risk Research .

Kahan, Dan, Hank Jenkins-Smith, Tor Tarantola, Carol Silva, and Donald Braman. 2015. "Geoengineering and Climate Change Polarization: Testing a Two-Channel Model of Science Communication." The Annals of the American Academy of Political and Social Science .

Kahan, Dan, and Paul Slovic. 2006. "Cultural Evalations of Risk: 'Values' or 'Blunders'?" Yale Law School, Public Law Working Papers .

Kahneman, Daniel, 2011. Thinking, Fast and Slow. Farrar, Straus and Giroux.

Keith, David, 2013. A Case for Climate Engineering. MIT Press.

Keith, David, and Mike Hulme, 2013. "Climate Science: Can Geoengineering Save the World?" Blog Post, available at https://www.theguardian.com/sustainablebusiness/blog/climate-science-geoengineering-save-world.

Kuhn, Thomas S., 1962. The Structure of Scientific Revolutions. The University of Chicago Press.

Lackey, Jennifer, 2008. Learning From Words: Testimony as a Source of Knowledge. Oxford University Press. 
Lackey, Jennifer, and David Christensen, 2013. The Epistemology of Disagreement: New Essays. Oxford University Press.

Lando, Tamar. 2016. "Coincidence and Common Cause." Noûs 50.

Lane, Lee, 2008. "Geoengineering as an Approach to Climate Change." In "Testimony given before House Select Committee on Energy Independence and Global Warming,"

Mercer, A.M., D.W. Keith, and J.D. Sharp. 2011. "Public Understanding of Solar Radiation Management." Environmental Research Letters .

Nozick, Robert, 1974. Anarchy, State and Utopia. New York: Basic Books.

Oreskes, Naomi, 2011. Merchants of Doubt: How a Handful of Scientists Obscured the Truth on Issues from Tobacco Smoke to Global Warming. Bloomsbury Press.

Owens, David, 1992. Causes and Coincidences. Cambridge University Press.

Pust, Joel. 2001. "Against Explanationist Skepticism Regarding Philosophical Intuitions." Philosophical Studies 106.

Street, Sharon. 2006. "A Darwinian Dilemma for Realist Theories of Value." Philosophical Studies 127:109-166.

Sunstein, Cass. 2006. "Misfearing: A Reply." Harvard Law Review .

Vavova, Ekaterina. 2016. "Irrelevant Influences." Philosopy and Phenomenological Research . 